which is rarely contraindicated with current anaesthetic techniques.

In those patients in whom long term catheterisation is inevitable most catheters require replacement in less than four weeks because of blockage or bypassing. ${ }^{14}$ There may also be more serious complications such as sepsis, but few studies have attempted to assess the risk. Hospital patients who are catheterised short term have an increased mortality because of the catheter, ${ }^{5}$ but the risks of long term catheterisation are more difficult to assess. ${ }^{6}$ Bacteriuria is unavoidable in over $90 \%$ of patients ${ }^{1}$ and is not prevented by antiseptics and antibiotics, which encourage multiply resistant organisms. (A possible exception is that antibiotics may be used in those with proteus infection as this may rapidly block catheters with triple phosphate encrustations.) Instilling antiseptic solutions into the drainage system, ${ }^{7}$ and using them for local cleaning of the urethral meatus ${ }^{8}$ or bladder lavage $e^{4}$ are also unsuccessful in preventing bacteriuria. Bladder lavage may, however, reduce the incidence and severity of catheter bypassing by preventing debris from accumulating. ${ }^{49}$

Opinions vary on which type of catheter to use long term. Repetitive catheterisation is traumatic and may cause false passages, urethral erosion, and strictures, and the risk of stricture formation is partly related to the toxicity of the catheter material. ${ }^{10}$ In the short term pure silicone catheters have proved superior in this respect to latex catheters. ${ }^{11}$ Of greater importance in long term catheterisation, however, is the incidence or blockage, and here the advantages of pure silicone over coated or uncoated latex are less apparent. ${ }^{24}$ The success of long term catheterisation is probably more closely linked to catheter care than to the type of catheter, particularly in the community, and a small (16F) latex catheter with a $5-10 \mathrm{ml}$ balloon is probably as effective as the more expensive alternatives.

The rate of catheter renewal varies between patients and is reasonably predictable for the individual..$^{12}$ Ferrie and colleagues defined two groups of patients according to the likelihood of catheter blockage or bypassing and recommended that for those who had a low incidence of complications the catheter could be checked fortnightly and changed every 8-12 weeks. ${ }^{9}$ For complicated cases they suggested thrice weekly bladder lavage with tap water and a change of catheter every four weeks. They also suggested spigoting the catheter during the day with three hourly emptying to prevent local trauma to the bladder and allow greater mobility.

A close relationship is needed between staff in the community and those in hospital so that specific problems such as leakage because of detrusor spasm and stone formation can be treated. The essential feature of a successful programme for long term catheter care is, however, that it is community based and dependent on district nursing staff who have specific training and expertise. ${ }^{9}$ If doctors and nurses think harder about who needs a long term catheter and about how to manage patients with long term catheters in the community then fewer hospital admissions will be necessary.

Senior Urological Registrar,

Leicester General Hospital,

Leicester LE5 4PW

1 Cools HJM, Van Der Meer JWM. Restriction of long-term indwelling urethral catheterisation in the elderly. Br $\mathcal{J}$ Urol 1986;58:683-8.

2 Kennedy AP, Brocklehurst JP. The nursing management of patients with longterm indwelling catheters. F Adv Nurs 1982;7:411-7.
3 Castleden CM, Duffin HM, Asher MJ. Clinical and urodynamic studies in 100 elderly patients. $\mathrm{Br}$ Med f 1981;282:1103-5.

4 Brocklehurst JC, Brocklehurst S. The management of indwelling catheters. Br $\mathcal{F}$ Urol 1978;50 102-5.

5 Platt R, Polk BF, Murdock B, Rosner B. Mortality associated with nosocomial urinary tract infection. N Engl $\mathcal{G}$ Med 1982;307:637-42.

6 Kunin CM. The incontinent patient and the catheter. F Am Geriatr Soc 1983;31:259-60.

7 Thompson RL, Haley CE, Searcy MA, et al. Catheter-associated bacteriuria. FAMA 1984;251: 747-51.

8 Burke JP, Garibaldi RA, Britt MR, Jacobson JA, Conti M. Prevention of catheter-associated urinary tract infections. Am $\mathcal{F}$ Med 1981;70:655-8.

9 Ferrie BG, Glen ES, Hunter B. Long-term urethral catheter drainage. Br f Med 1979;ii: 1046-7. 10 Blacklock NJ. Catheters and urethral strictures. Br J Urol 1986;58:475-8.

11 Ferrie BG, Groome J, Sethia B, Kirk D. Comparison of silicone and latex catheters in the development of urethral stricture after cardiac surgery. Br $\mathcal{J}$ Urol 1986;58:549-50.

12 Norberg B, Norberg A, Parkhede U. The spontaneous variation of catheter life in long-stay geriatric inpatients with indwelling catheters. Gerontology 1983;29:332-5.

\section{Testing the sense of smell}

The methods routinely used for testing the sense of smell are inadequate. Doctors may think that smell is the least important of the senses, but the patient with an olfactory disorder has a different view. He or she can no longer enjoy everyday odours and may worry about being unable to detect spoilt food, leaking gas, or a fire. Patients presenting with taste disorders also need to have their sense of smell tested because in some of them it is this that is at fault. Some patients who complain of a change in their sense of smell have serious medical conditions: intranasal or intracranial neoplasms, endocrine disorders (Turner's syndrome, Kallman's syndrome, hypothyroidism, or adrenal hyperplasia), Parkinson's disease, Korsakoff's psychosis, or Alzheimer's disease. Finally, objective assessment of smell has medicolegal importance when impairment of smell is alleged to have resulted from accident or injury.

Most patients at the moment will have their complaints of smell disorder assessed with a hastily dusted set of four bottles. These present a suprathreshold stimulus and elicit only an "all or none" response; subtle degrees of olfactory loss will be missed, and many patients will have their complaints dismissed when tested in this way. A more accurate means of assessment is necessary, but nearly a century and a half after Valentin's pioneering work ${ }^{1}$ smell testing is still beset with technical difficulties of controlling and presenting the stimulus and of identifying and measuring the patient's response.

To present odours of known identity and intensity specialist research centres use air dilution olfactometerscomplex and expensive items that need tedious and meticulous maintenance and cleaning. ${ }^{2}$ Finding the best way of assessing the patient's perception of an olfactory stimulus has occupied psychophysicists for decades. One attractive proposition would be cerebral olfactory evoked potentialsanalogous to auditory and optical evoked responses-but as yet they remain an elusive goal. Responses are variable, and there are problems in differentiating olfactory from trigeminal evoked responses.

These methods are in any case impractical for routine work. An important advance on the old smell bottles has been the use of microencapsulated odorants mounted on card which are presented in a "scratch and sniff" booklet of 40 different smells (available from Sensonics Inc, 155 Hadden Avenue, Huddersfield, New Jersey 08033, USA). ${ }^{3}$ After scratching a card and smelling the odour released subjects must choose one of four possible alternative identifications. Anosmic patients get about a quarter right by chance alone; 
the test therefore picks out all but the most sophisticated malingerers because most choose wrong answers throughout and score near zero. Normal people identify 35-40 correctly, and patients with partial anosmia score 15-35. One advantage is that after simple instruction the patient can perform the test unsupervised. Also available are sets of plastic squeeze bottles producing serial dilutions of pyridine vapour. ${ }^{4}$ These measure the threshold concentration at which an odour can be detected, but for the non-specialist centre this test has little advantage over the scratch and sniff tests.

Finally, merely testing the sense of smell is not synonymous with investigating a complaint of olfactory disorder. All patients need a history taken and examination performed, with particular reference to neurological and nasopharyngeal problems. When no cause can be found for demonstrable olfactory loss, or when the patient's complaint persists despite negative findings on simple tests, referral to a specialist centre for more detailed assessment is necessary. Smell, the Cinderella of the senses, should be taken seriously.

Senior Registrar,

VICTORIA MOORE-GILLON

Professorial Unit,

Royal National Throat, Nose and Ear Hospital,

London WC1X 8EE

and

Department of Otorhinolaryngology,

St George's Hospital,

London SW17 0QT

1 Valentin GG. Lehrbuch der Physiologie. 2nd ed. Braunschweig: F Vicweg 1848

2 Douek E. The sense of smell and its abnormalities. London: Churchill Livingstone, 1974.

3 Doty RL, Shaman P, Kimmelman CP, Dann MS. University of Pennsylvania smell identification test: a rapid quantitative olfactory function test for the clinic. Laryngoscope 1984;94:176-8.

4 Amoore JE, Ollman BG. Practical test kits for quantitatively evaluating the sense of smell. Rhinology1983;21:49-54.

\section{Sterilisation and the mentally handicapped}

Last week's authorisation by the Court of Appeal that a severely mentally handicapped girl could be sterilised weeks before her 18th birthday evoked widespread comment and illustrated many of the anxieties and myths that surround the sexuality of the mentally handicapped ( $p$ 825). Coincidentally, this month has also seen the publication of a level headed scholarly book on mental handicap and sexuality edited by Ann Craft, ${ }^{1}$ who has done much of the pioneering work on this often ignored subject. ${ }^{2}$ She describes the two contradictory myths that tend to influence many discussions on the sexuality of the mentally handicapped: firstly, that they have strong sexual inclinations combined with lack of control; and, secondly, that they are in some sense children and so should not display any sexual tendencies. In fact, most mentally handicapped people are only mildly to moderately retarded and given the right circumstances and education can enjoy sex lives. My records for the last 10 years of working with mentally handicapped people show that I have only once recommended sterilisation-and that was to a mentally handicapped couple who already had two children. I suggested that the man should have a vasectomy, but they decided that the woman would be sterilised.
Contraception will usually do away with the need for sterilisation. Contraceptives-for example, intrauterine devices-can be used in even the most severely mentally handicapped. ${ }^{3}$ Sometimes medroxyprogesterone acetate (Depo-Provera) will be necessary, but the contraceptive pill is best avoided because of possible interactions with anticonvulsants and antibiotics. Moreover, it is always a problem whether a mentally handicapped woman will take the pill regularly. Unfortunately because of the prevailing myths many people find it difficult to think about contraception when dealing with the mentally handicapped.

Craft describes four ways in which people, including parents and carers, may respond to the sexuality of the mentally handicapped: elimination, toleration, acceptance, or cultivation. ${ }^{1}$ Cultivation is rare, yet mentally handicapped people should have the same sexual rights as anybody else, which includes the right to sex education. The United Nations in 1971 stated in its declaration of the rights of mentally handicapped people: "The mentally retarded person has the same basic rights as other citizens of the same country and same age." Most studies of the sex education of the mentally handicapped show it to be woefully inadequate, ${ }^{1}$ and yet it can be done. Craft points to the difference between understanding and behaviour: just as many people drive cars successfully all their lives with little or no understanding of how a car works so a mentally handicapped person can be taught to behave sexually in an acceptable manner without understanding some of the complexities of sexuality. ${ }^{1}$

The mentally handicapped also have other sexual rightsnot to be abused and to have access to circumstances in which they can be sexually active in private. They are very vulnerable to sexual abuse and have often had to live in circumstances that made expressing sexuality difficult. Much research shows that the more normal the environments experienced by people-including the mentally handicapped-the more normal their behaviour. ${ }^{1}$ This is why community care in normal housing and by proper care staff is so important.

Sterilisation may be necessary in a tiny number of cases when all else has failed. The decision to sterilise a mentally handicapped person is extremely difficult, and all those caring for the person will need to participate. Indeed, for minors the parents or carers will have to apply to the courts; for adults the law is not clear (p 825). Proper counselling is essential before sterilisation, and the counsellor must consider several aspects: the person's fertility; whether consent can be informed; and the effect on sexual functioning. ${ }^{4}$ Sometimes mentally handicapped couples request sterilisation so that parenthood will not threaten their capacity to cope, ${ }^{2}$ and sterilisation should be available to all but imposed without consent in only the most exceptional circumstances. And, to repeat, contraception will almost always do away with the need for sterilisation.

\section{Debabrata Chakraborti}

Consultant Psychiatrist in Mental Handicap,

Windsor Unit,

King's Lynn,

Norfolk PE30 5QD

1 Craft A. Mental handicap and sexuality. Tunbridge Wells, Kent: Costello, 1987.

2 Craft A, Craft M. Handicapped married couples. London: Routledge and Kegan Paul, 1979. Chakraborti D, Macdonald AP. Contraception and the mentally handicapped. Br Med 1984;289:1095-6.

4 Andron L. Sexuality counselling with developmentally disabled couples. In: Craft A, Craft M, eds. Sex education and counselling for mentally handicapped people. Tunbridge Wells, Kent: Costello, 1983. 